\title{
Effect of Lachancea thermotolerans on the Formation of Polymeric Pigments during Sequential Fermentation with Schizosaccharosmyces pombe and Saccharomyces cerevisiae
}

\author{
Carlos Escott ${ }^{1, *(1)}$, Antonio Morata $\left.{ }^{1}{ }^{(}\right)$, Jorge M. Ricardo-da-Silva $\left.{ }^{2}{ }^{(}\right)$, María Jesús Callejo ${ }^{1}$, \\ María del Carmen González ${ }^{1}$ and José Antonio Suarez-Lepe ${ }^{1}$ \\ 1 enotecUPM. Chemistry and Food Technology Department, School of Agronomic, Food and Biosystems \\ Engineering. Universidad Politécnica de Madrid, Av. Puerta de Hierro 2, 28040 Madrid, Spain; \\ antonio.morata@upm.es (A.M.); mj.callejo@upm.es (M.J.C.); carmen.gchamorro@upm.es (M.d.C.G.); \\ joseantonio.suarez.lepe@upm.es (J.A.S.-L.) \\ 2 LEAF-Linking Landscape, Environment, Agriculture and Food, Instituto Superior de Agronomia, \\ Universidade de Lisboa, Tapada da Ajuda, 1349-017 Lisboa, Portugal; jricardosil@isa.ulisboa.pt \\ * Correspondence: c.escott@alumnos.upm.es; Tel.: +34-91-336-57-30; Fax: +34-91-336-57-46
}

Received: 30 July 2018; Accepted: 12 September 2018; Published: 14 September 2018

\begin{abstract}
Anthocyanins in red grape musts may evolve during the winemaking process and wine aging for several different reasons; colour stability and evolution is a complex process that may depend on grape variety, winemaking technology, fermentative yeast selection, co-pigmentation phenomena and polymerization. The condensation of flavanols with anthocyanins may occur either with the flavylium ion or with the hemiacetal formation in order to produce oligomers and polymers. The kinetics of the reaction are enhanced by the presence of metabolic acetaldehyde, promoting the formation of pyranoanthocyanin-type dimers or flavanol-ethyl-anthocyanin structures. The experimental design carried out using white must corrected with the addition of malvidin-3-O-glucoside and flavanols, suggests that non-Saccharomyces yeasts are able to provide increased levels of colour intensity and larger polymeric pigment ratios and polymerization indexes. The selection of non-Saccharomyces genera, in particular Lachancea thermotolerans and Schizosaccharomyces pombe in sequential fermentation, have provided experimental wines with increased fruity esters, as well as producing wines with potential pigment compositions, even though there is an important reduction of total anthocyanins.
\end{abstract}

Keywords: malvidin; polymeric pigments; non-Saccharomyces; red wine; flavanols

\section{Introduction}

There are different factors that determine the colour evolution and colour stability of red wines, including grape variety as a sole source of anthocyanins [1]; practices during the winemaking process such as tannin addition [2] or cold maceration [3]; the selection of fermentative yeast strains that promote the formation of stable pigments through the production of metabolites, such as pyruvic acid or acetaldehyde [4], or that promote changes in pigment composition through the adsorption of anthocyanins through the yeast cell walls [5]; and co-pigmentation phenomena [6].

Yeast metabolism may lead to different values of metabolic precursors during must fermentation for the formation of pyranoanthocyanins, oligomeric and polymeric pigments. Non-Saccharomyces yeasts have been shown to produce a concentration of pyruvic acid and acetaldehyde that is different from Saccharomyces cerevisiae [7-10]. Escott et al. [11] found a higher concentration of stable pigments 
produced during fermentation with non-Saccharomyces yeasts in comparison to pure fermentations with S. cerevisiae.

Although the reactivity of the flavylium ion may be different from that of the hemiacetal form, both molecules interact with flavanols to form oligomers in suspension; in fact, according to Es-Safi and Cheynier [12], dimers are also formed from the condensation of a hemiacetal moiety with flavanols. The latter products, initially belonging to the non-coloured fraction, would be displaced into the coloured form through a co-pigmentation equilibrium [13] that takes place in typical red wine $\mathrm{pH}$ and acid aqueous solutions. The dimers formed by the nucleophilic addition of anthocyanins in their hemiacetal form to produce flavanol-anthocyanin adducts (F-A ${ }^{+}$) were reported by Salas et al. [14]. These non-acetaldehyde-mediated oligomers are produced when the flavanol carbocation $\left(\mathrm{F}^{+}\right)$interacts with positions $\mathrm{C} 6$ and/or C8 of anthocyanins

Oligomer pigments are more stable, not as a consequence of their larger molecular weight, but due to the fact that position 4, C4 in the pyran ring of anthocyanins, is protected by the formation of ethyl-linked oligomeric derivatives or the formation of pyranoanthocyanins [15]. Dimeric pigments formed through the condensation of two malvidin-3-O-glucoside molecules were found in wine-like solutions and red wines and described by Atanasova et al. [16]. The dimer helped prove the existence of acetaldehyde-mediated, self-condensed anthocyanins. The structure described was formed by two malvidin-3-O-glucoside moieties linked by an acetaldehyde molecule at positions $\mathrm{C} 8$ in both anthocyanins. The colour retention observed in pyranoanthocyanins at higher $\mathrm{pH}$ values could be explained by the fact that these pigments may not undergo hydration reactions [17], which explains their higher stability against monomeric anthocyanins.

The aim of the work was to use white grape must to monitor the condensation of malvidin-3-O-glucoside with four different flavanols during fermentation with pure S. cerevisiae culture as control, and sequential fermentations with non-Saccharomyces yeasts. The flavanols tested in this experiment design were $(+)$-catechin, procyanidin B2, procyanidin $\mathrm{C} 1$ and procyanidin $\mathrm{A} 2$.

\section{Results and Discussion}

\subsection{Yeast Growth and Metabolite Production}

The growth kinetics of the yeast populations can be seen in Figure 1. There were three different fermentation trials, one of which was the pure culture of Sc and two other sequential fermentations with $\mathrm{Lt}+\mathrm{Sc}$ and $\mathrm{Lt}+\mathrm{Sp}$. It was found that within three days, Sc as well as Lt achieved maximum growth with $6.4 \times 107 \mathrm{CFU} / \mathrm{mL}$ and $4.5 \times 107 \mathrm{CFU} / \mathrm{mL}$, respectively, but neither case had a stationary phase, as had been observed previously for pure culture and co-fermentations of Saccharomyces cerevisiae by Sadineni et al. [9]; a rapid decrease in Sc populations after day 7 was observed, resulting in an average of $1 \times 105 \mathrm{CFU} / \mathrm{mL}$ at day 9 . With regard to the sequential fermentation with Sc, there was a slight increase and steady growth observed in the CAT and PB2 treatments, while for the other treatments, including Sp, there was a slower decrease in yeast populations over time, until the population numbers ranged between $1 \times 105$ and $1 \times 106 \mathrm{CFU} / \mathrm{mL}$ after day 13 ; this might be due to the fact that the increasing concentration of ethanol makes it difficult for Lachancea spp., and several other non-Saccharomyces yeasts such as M. pulcherrima, T. delbrueckii and C. zemplinina [18], to survive over fermentation time. 

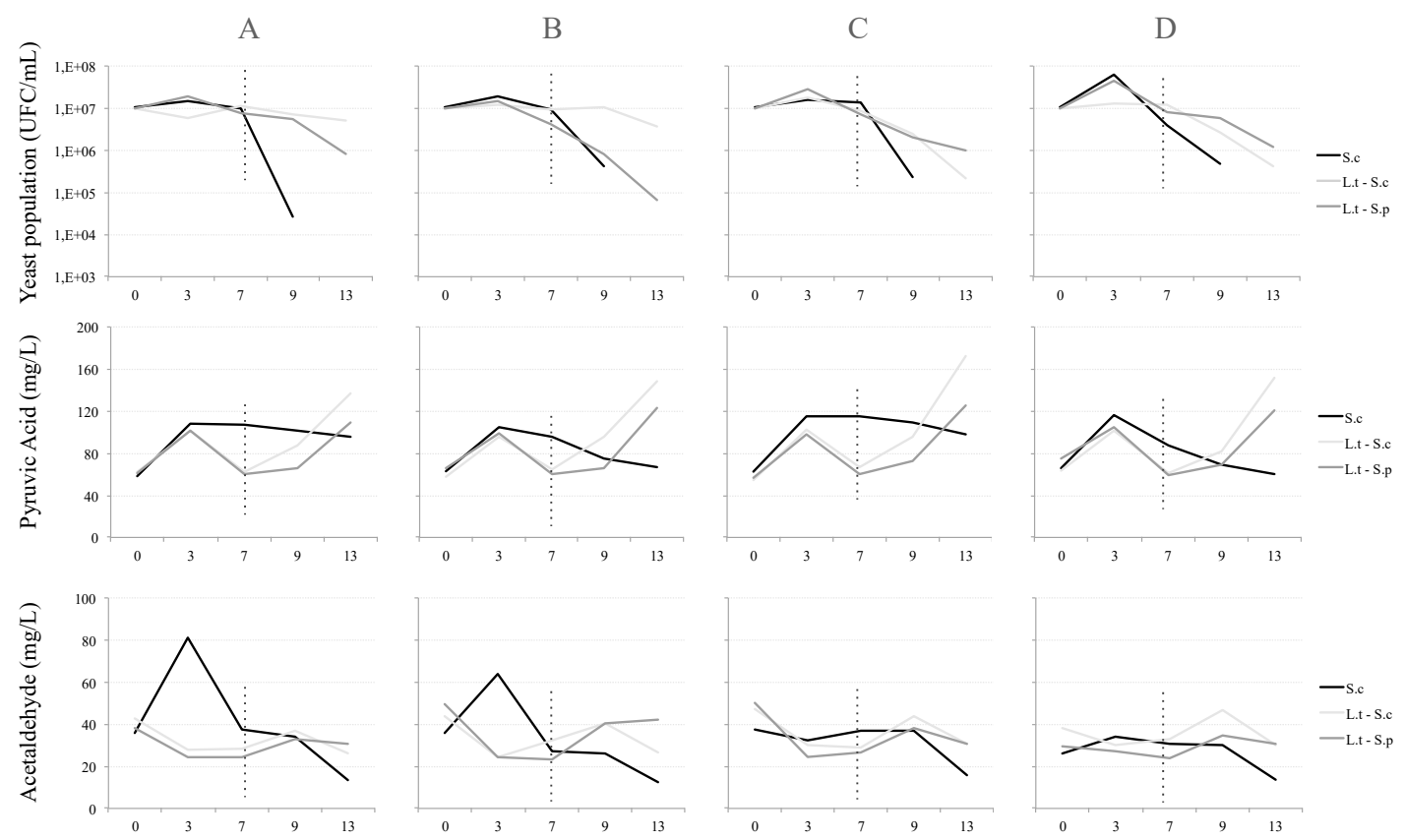

Time of fermentation (days)

Figure 1. Yeast population growth. Data from acetaldehyde and pyruvic acid concentrations during fermentation. Analyses performed with gas chromatography (GC-FID) (acetaldehyde), enzymatic analyser (pyruvic acid) and plate counting (cells growth). Each point represents mean values $(n=3)$. Dotted lines indicate the sequential yeast inoculation. (A) CAT, (B) PB2, (C) PC1 and (D) PA2.

The production of fermentative metabolites followed the kinetic growth, reaching a maximum concentration after $72 \mathrm{~h}$, although no increases were observed in the production of these metabolites after sequential inoculation. Pyruvic acid reached the maximum concentration in all treatments for both yeasts in the initial phase: Sc reached $116 \mathrm{mg} / \mathrm{L}$ and $\mathrm{Lt}$ reached $105 \mathrm{mg} / \mathrm{L}$. With regard to acetaldehyde production, the maximum concentration was observed in CAT and PB2 treatments for pure culture Sc $(81.1 \mathrm{mg} / \mathrm{L}$ and $63.6 \mathrm{mg} / \mathrm{L}$ respectively), and steady amounts for PC1 and PA2. The concentration of pyruvic acid increased after the sequential inoculation of yeasts Sc (>140 mg/L) and $\mathrm{Sp}(>110 \mathrm{mg} / \mathrm{L})$ in all treatments, with the exception of pure culture Sc, where a steady phase and slight decrease was observed after $72 \mathrm{~h}$ and across the remaining fermentation time. On the other hand, when using Lt, the concentration of acetaldehyde decreased during the initial fermentative phase. This is likely due to the fact that the production of acetaldehyde is proportional to the sugars fermented [5], and also because Lt decreases its metabolism when the ethanol concentration increases. After the sequential inoculation of yeasts (Sc and Sp), acetaldehyde production increased and reached its peak at day 9 (Figure 1) with values of ca. $40 \mathrm{mg} / \mathrm{L}$.

\subsection{Ethanol, Acidity and Sugar Content}

Sequential fermentation carried out with the species Lt-Sp resulted in residual sugar (both glucose and fructose combined) higher than $4 \mathrm{~g} / \mathrm{L}$, which led to a lower ethanol content compared to the other fermentations (Lt-Sc and pure Sc), however, statistical differences were not evident (Table 1). The differences found in the acidic composition depended on the yeast species used to carry out the fermentations and was independent of the flavanols used in each treatment. Volatile acidity, as well as total acidity were statistically higher for the fermentations carried out with Sc $(>0.6 \mathrm{~g} / \mathrm{L})$, while the $\mathrm{Lt}-\mathrm{Sp}$ combination had the lowest concentrations for both parameters; these values were similar to those observed by Sun, Gong, Jiang, and Zhao [19], with more than $0.55 \mathrm{~g} / \mathrm{L}$ for pure culture fermentation with the strain of S. cerevisiae and mixed fermentation with a strain of M. pulcherrima. On the other hand, lactic acid was statistically higher for those fermentations where Lachancea thermotolerans was 
used as the starter culture (Lt-Sc and Lt-Sp) compared to pure Sc fermentation. The malic acid content was statistically lower for the Lt-Sp pair and therefore the $\mathrm{pH}$ values were higher in these fermentations compared to fermentations with Sc. The demalication observed during the last few trials was performed by Schizosaccharomyces pombe, through which malic acid was transformed into ethanol and $\mathrm{CO}_{2}[10]$.

Table 1. Ethanol, acidity and sugar content in wine samples. Results are shown by treatment. The statistical analysis was performed by parameter (columns) and the different letters indicate significant statistical difference (LSD method with method with $95 \%$ confidence level). Means \pm standard deviation (STD) $(n=3)$.

\begin{tabular}{|c|c|c|c|c|c|c|c|c|}
\hline Treatment & $\begin{array}{l}\text { EtOH } \\
\% v / v\end{array}$ & $\mathrm{pH}$ & $\begin{array}{l}\text { Malic Acid } \\
\text { g/L }\end{array}$ & $\begin{array}{c}\text { Volatile } \\
\text { Acidity } \\
\text { g/L }\end{array}$ & $\begin{array}{c}\text { Lactic Acid } \\
\mathrm{g} / \mathrm{L}\end{array}$ & $\begin{array}{c}\text { Total } \\
\text { Acidity } \\
\text { g/L }\end{array}$ & $\begin{array}{c}\text { Glucose } \\
\text { g/L }\end{array}$ & $\begin{array}{c}\text { Fructose } \\
\mathrm{g} / \mathrm{L}\end{array}$ \\
\hline \multicolumn{9}{|l|}{ CAT } \\
\hline Lt-Sc & $14.0 \pm 0.2 \mathrm{a}$ & $3.6 \pm 0.0 \mathrm{c}$ & $1.7 \pm 0.1 \mathrm{~d}$ & $0.2 \pm 0.0 \mathrm{c}$ & $0.8 \pm 0.1 \mathrm{a}$ & $4.9 \pm 0.1 \mathrm{bc}$ & $0.8 \pm 0.1 b$ & $1.2 \pm 0.2 \mathrm{~b}$ \\
\hline $\begin{array}{l}\text { Lt-Sp } \\
P B 2\end{array}$ & $13.7 \pm 0.1 \mathrm{a}$ & $3.8 \pm 0.0 \mathrm{a}$ & $0.7 \pm 0.1 \mathrm{f}$ & $0.2 \pm 0.0 \mathrm{c}$ & $0.8 \pm 0.1 \mathrm{a}$ & $3.4 \pm 0.1 \mathrm{~d}$ & $3.5 \pm 0.2 \mathrm{a}$ & $10.8 \pm 0.8 \mathrm{a}$ \\
\hline $\begin{array}{l}\text { Lt-Sp } \\
P C 1\end{array}$ & $13.8 \pm 0.3 \mathrm{a}$ & $3.8 \pm 0.0 \mathrm{a}$ & $0.7 \pm 0.0 \mathrm{f}$ & $0.2 \pm 0.0 \mathrm{c}$ & $0.7 \pm 0.0 \mathrm{a}$ & $3.4 \pm 0.1 \mathrm{~d}$ & $3.1 \pm 0.5 \mathrm{a}$ & $10.2 \pm 0.8 \mathrm{a}$ \\
\hline Sc & $14.2 \pm 0.2 \mathrm{a}$ & $3.7 \pm 0.0 \mathrm{bc}$ & $2.1 \pm 0.1 \mathrm{a}$ & $0.6 \pm 0.1 \mathrm{ab}$ & $0.5 \pm 0.0 \mathrm{~b}$ & $5.2 \pm 0.1 \mathrm{a}$ & $1.0 \pm 0.2 \mathrm{~b}$ & $2.6 \pm 1.1 \mathrm{~b}$ \\
\hline Lt-Sc & $14.4 \pm 0.1 \mathrm{a}$ & $3.6 \pm 0.0 \mathrm{c}$ & $1.8 \pm 0.2 \mathrm{bcd}$ & $0.2 \pm 0.0 \mathrm{c}$ & $0.8 \pm 0.1 \mathrm{a}$ & $4.8 \pm 0.1 \mathrm{c}$ & $1.0 \pm 0.2 \mathrm{~b}$ & $1.8 \pm 0.7 \mathrm{~b}$ \\
\hline $\begin{array}{l}\text { Lt-Sp } \\
P A 2\end{array}$ & $13.9 \pm 0.3 \mathrm{a}$ & $3.8 \pm 0.0 \mathrm{ab}$ & $0.6 \pm 0.1 \mathrm{f}$ & $0.2 \pm 0.0 \mathrm{c}$ & $0.8 \pm 0.1 \mathrm{a}$ & $3.4 \pm 0.1 \mathrm{~d}$ & $2.8 \pm 0.8 \mathrm{a}$ & $10.1 \pm 0.7 \mathrm{a}$ \\
\hline
\end{tabular}

CAT. (+)-catechin, PB 2: procyanidin B2, PC 1: procyanidin C1, PA 2: procyanidin A2.

\subsection{Fermentative Volatiles}

A summary of the fermentative volatiles is given in Table 2, and have been grouped into four different categories: higher alcohols, carbonyl compounds, fruity esters and total volatiles. Higher alcohols, except 2,3-butanediol, had in all trials concentrations below the $350 \mathrm{mg} / \mathrm{L}$ threshold [20,21], therefore it was not expected that they would contribute to an aromatic defect of the wines. The fermentative Lt-Sc yeast combination produced the highest concentration of total higher alcohols (between $227.7 \pm 5.3$ and $253.9 \pm 8.3 \mathrm{mg} / \mathrm{L}$ ), while fermentations done with Sc produced the lowest concentrations (between $135.9 \pm 4.4$ and $179.8 \pm 4.6 \mathrm{mg} / \mathrm{L}$ ). Acetoin, diacetyl and ethyl acetate were grouped as carbonyl compounds; when these molecules are higher in concentration than their threshold value, it can result in off-aromas in red wine. Ethyl acetate is a compound with a fruity aroma and can also be linked to solvent or glue in high concentrations [22]; according to Benito, Morata, Palomero, Gonzalez, and Suárez-Lepe [23], acetoin, with a threshold of $10 \mathrm{mg} / \mathrm{L}$, and diacetyl, with a threshold in wines of $2 \mathrm{mg} / \mathrm{L}$, could be responsible for buttery aromas. Regarding single molecules, in contrast to the values of ethyl acetate higher than $125 \mathrm{mg} / \mathrm{L}$ obtained in sequential fermentations when using Metschnikowia pulcherrima [11], the concentrations obtained in these trials were between $24.4 \pm 0.1 \mathrm{mg} / \mathrm{L}$ and $49.4 \pm 1.6 \mathrm{mg} / \mathrm{L}$; wines made with the Lt-Sp combination were lower, while Lt-Sc wines were the highest. These concentrations are similar to the values observed by Loira et al. [7] for fermentations involving Torulaspora delbrueckii and Saccharomyces cerevisiae, with values between $6 \mathrm{mg} / \mathrm{L}$ and $30 \mathrm{mg} / \mathrm{L}$. In terms of diacetyl, the fermentative pair Lt-Sc had higher values that were statistically different; the values ranged from $5.2 \pm 0.3 \mathrm{mg} / \mathrm{L}$ to $11.3 \pm 0.1 \mathrm{mg} / \mathrm{L}$, all of which were higher than the threshold and may be noticed by the consumer. According to Bartowski and Henschke [24], diacetyl can provide a buttery aroma and flavour to a series of fermented foods and beverages, but is also an intermediate in the production of acetoin and the further production of 2,3-butanediol. The concentration of acetoin produced was slightly higher than the other fermentations, yet statistically significant for the fermentative Lt-Sp yeast combination with values between $7.5 \pm 0.2 \mathrm{mg} / \mathrm{L}$ and $8.1 \pm 0.3 \mathrm{mg} / \mathrm{L}$, meaning all wines were lower in acetoin than the threshold. The values for these three compounds 
together were statistically higher for the combination Lt-Sc, especially due to the higher concentrations of ethyl acetate and diacetyl produced during fermentation.

Table 2. Summary of fermentative volatile compounds quantified by GC-FID. The statistical analysis is given by parameter (columns) and the difference in letters indicates significant statistical difference (LSD method with 95\% confidence level). Means $\pm \operatorname{STD}(n=3)$.

\begin{tabular}{|c|c|c|c|c|}
\hline Treatment & $\begin{array}{c}\text { Higher Alcohols }^{1} \\
\mathrm{mg} / \mathrm{L}\end{array}$ & $\begin{array}{c}\text { Carbonyl Compounds }{ }^{2} \\
\mathrm{mg} / \mathrm{L}\end{array}$ & $\begin{array}{c}\text { Fruity Esters }{ }^{3} \\
\text { mg/L }\end{array}$ & $\begin{array}{l}\text { Total Volatiles } \\
\text { mg/L }\end{array}$ \\
\hline \multicolumn{5}{|l|}{ (+)-Catechin } \\
\hline $\mathrm{Sc}$ & $135.9 \pm 4.4 \mathrm{f}$ & $42.0 \pm 1.7 \mathrm{c}$ & $8.7 \pm 0.6 c$ & $1316.6 \pm 91,4 \mathrm{c}$ \\
\hline Lt-Sc & $253.9 \pm 8.3 \mathrm{a}$ & $59.8 \pm 1.9 \mathrm{a}$ & $15.8 \pm 0.4 \mathrm{~b}$ & $1048.6 \pm 11.2 \mathrm{~d}$ \\
\hline Lt-Sp & $196.1 \pm 1.7 \mathrm{c}$ & $38.4 \pm 0.6 \mathrm{~cd}$ & $27.1 \pm 1.2 \mathrm{a}$ & $933.5 \pm 7.4 \mathrm{e}$ \\
\hline \multicolumn{5}{|l|}{ PB2 } \\
\hline Sc & $154.9 \pm 4.1 \mathrm{e}$ & $46.7 \pm 0.8 \mathrm{~b}$ & $8.4 \pm 0,9 c$ & $1615.7 \pm 64.0 \mathrm{~b}$ \\
\hline Lt-Sc & $227.7 \pm 5.3 b$ & $62.2 \pm 1.5 \mathrm{a}$ & $14.7 \pm 0.4 b$ & $1028.1 \pm 9.1 \mathrm{de}$ \\
\hline Lt-Sp & $203.0 \pm 5.6 c$ & $36.6 \pm 1.5 \mathrm{~d}$ & $23.6 \pm 0.7 \mathrm{a}$ & $987.7 \pm 7.4 \mathrm{de}$ \\
\hline \multicolumn{5}{|l|}{$P C 1$} \\
\hline Sc & $137.3 \pm 1.0 \mathrm{f}$ & $36.8 \pm 0.6 \mathrm{~d}$ & $7.5 \pm 0.6 c$ & $1421.5 \pm 53.5 c$ \\
\hline Lt-Sc & $233.7 \pm 3.8 \mathrm{~b}$ & $58.3 \pm 1.0 \mathrm{a}$ & $14.0 \pm 0.7 \mathrm{~b}$ & $1047.9 \pm 11.7 \mathrm{de}$ \\
\hline Lt-Sp & $209.2 \pm 4.8 c$ & $36.5 \pm 1.0 \mathrm{~d}$ & $24.6 \pm 0.5 \mathrm{a}$ & $981.7 \pm 34.4 \mathrm{de}$ \\
\hline \multicolumn{5}{|l|}{$P A 2$} \\
\hline Sc & $179.8 \pm 4.6 \mathrm{~d}$ & $50.5 \pm 0.8 b$ & $8.8 \pm 0.4 c$ & $1746.0 \pm 16.0 \mathrm{a}$ \\
\hline Lt-Sc & $232.0 \pm 7.6 \mathrm{~b}$ & $58.4 \pm 1.9 \mathrm{a}$ & $17.7 \pm 1.6 \mathrm{~b}$ & $1033.4 \pm 18.3 \mathrm{de}$ \\
\hline Lt-Sp & $206.8 \pm 2.9 c$ & $38.4 \pm 1.8 \mathrm{~cd}$ & $27.2 \pm 1.7 \mathrm{a}$ & $1022.0 \pm 15.1 \mathrm{de}$ \\
\hline
\end{tabular}

1 Higher alcohols comprise the following compounds: 1-propanol, 2-buntanol, isobutanol, 1-butanol, 2-methyl-1-butanol, 3-methyl-1-butanol,2-phenylethylalcohol; ${ }^{2}$ Carbonyl compounds comprise: diacetyl, acetoin, ethyl acetate; and ${ }^{3}$ Fruity esters comprise: isobutyl acetate, ethyl butyrate, ethyl lactate, isoamyl acetate, 2-phenylethyl acetate.

Fruity esters were present in higher concentration in wines produced with Lt-Sp combinations, followed by Lt-Sc wines, compared to Sc wines. As with higher alcohols and carbonyl compounds, the fruity ester concentration seems to depend on the fermentative yeast used for wine fermentation and not on the treatment. The highest concentrations were obtained with two non-Saccharomyces yeasts yielding concentrations between $23.6 \pm 0.7 \mathrm{mg} / \mathrm{L}$ and $27.2 \pm 1.7 \mathrm{mg} / \mathrm{L}$. Among the fruity esters evaluated, coffee or strawberry and raspberry aromas are produced by ethyl lactate [25]; rose, honey and apple aromas may be derived from 2-phenylethyl acetate [26], and according to Boss et al. [27], the overall contribution of esters to wine is expected to be fruity and flowery.

The concentration of total volatiles mostly consisted of 2,3-butanediol. The total fermentative volatiles were higher in wines produced with Sc given that this yeast produced higher concentrations of 2,3-butanediol (>1000 mg/L), compared to the concentration of higher alcohols and carbonyl compounds, which was higher in wines fermented with Lt-Sc. Wines fermented with Lt-Sp were higher in fruity esters. In these trials, Sc yeasts reduced acetoin to 2,3-butanediol to a larger extent than for the other fermentations, as was noted in fermentations performed with genetically engineered Saccharomyces cerevisiae strains [28]. This was due to the enzyme acetoin reductase, which reduces acetoin to 2,3-butanediol, involved in the metabolic pathway from pyruvate [29].

\subsection{Characterization of Pigments}

The cell walls of the yeast strains may adsorb anthocyanins to different extents [30], with some of these adsorbing up to three times more than others [31]. This suggests that the reduction of pigments during fermentation may be conditioned to the fermentative strains selected. This is the case observed in this experiment, especially when using the fermentative strains Lt-Sp, where a significant reduction in the concentration of malvidin-3-O-glucoside and total pigments was observed (Table 3). The use of $\mathrm{Lt}$ in the initial phase may lead to the first reduction in total pigments, later accentuated during a sequential fermentation with Sp. The CAT treatment was the only one where monomeric malvidin derivatives, other than malvidin-3-O-glucoside, were found; the pigment identified in these trials was malvidin-3-O-( $p$-coumaroyl)-glucoside with molecular ion $[\mathrm{M}]^{+}(\mathrm{m} / z) 639$ and fragment $\operatorname{ion}(m / z) 331$ [32]. 
Table 3. Summary of pigments found in experimental red wines. The statistical analysis is given by parameter (columns) and the difference in letters indicates significant statistical difference (LSD method with $95 \%$ confidence level). Means $\pm \operatorname{STD}(n=3)$.

\begin{tabular}{|c|c|c|c|c|}
\hline Treatment & Malvidin ${ }^{1} \mathrm{mg} / \mathrm{L}$ & Vitisins mg/L & Vinylphenolics mg/L & $\begin{array}{c}\text { Oligomeric Pigments } \\
\mathrm{mg} / \mathrm{L}\end{array}$ \\
\hline \multicolumn{5}{|l|}{ CAT } \\
\hline $\mathrm{Sc}$ & $28.7 \pm 1.8 \mathrm{~b}$ & $0.1 \pm 0.0 \mathrm{abc}$ & $0.3 \pm 0.0 \mathrm{ab}$ & $1.0 \pm 0.1 \mathrm{a}$ \\
\hline Lt-Sc & $25.9 \pm 0.8 c$ & $0.1 \pm 0.0 \mathrm{bc}$ & $0.2 \pm 0.0 \mathrm{e}$ & $0.8 \pm 0.0 \mathrm{~b}$ \\
\hline Lt-Sp & $14.0 \pm 0.7 \mathrm{~d}$ & $0.1 \pm 0.0 \mathrm{abc}$ & $0.0 \pm 0.0 \mathrm{f}$ & $0.6 \pm 0.1 \mathrm{~d}$ \\
\hline \multicolumn{5}{|l|}{ PB 2} \\
\hline Sc & $29.7 \pm 0.3 \mathrm{ab}$ & $0.1 \pm 0.0 \mathrm{ab}$ & $0.4 \pm 0.1 \mathrm{a}$ & $0.7 \pm 0.0 \mathrm{~cd}$ \\
\hline Lt-Sc & $26.7 \pm 0.6 c$ & $0.0 \pm 0.0 \mathrm{c}$ & $0.2 \pm 0.0 \mathrm{~cd}$ & $0.6 \pm 0.0 \mathrm{~d}$ \\
\hline Lt-Sp & $14.7 \pm 1.3 \mathrm{~d}$ & $0.1 \pm 0.0 \mathrm{abc}$ & $0.0 \pm 0.0 \mathrm{f}$ & $0.6 \pm 0.0 \mathrm{~d}$ \\
\hline \multicolumn{5}{|l|}{$P C 1$} \\
\hline Sc & $30.8 \pm 0.5 \mathrm{a}$ & $0.1 \pm 0.0 \mathrm{a}$ & $0.2 \pm 0.0 \mathrm{bc}$ & $0.7 \pm 0.0 c$ \\
\hline LtSc & $26.4 \pm 0.3 c$ & $0.1 \pm 0.0 \mathrm{abc}$ & $0.2 \pm 0.0 \mathrm{de}$ & $0.6 \pm 0.1 \mathrm{~cd}$ \\
\hline LtSp & $13.7 \pm 0.6 \mathrm{~d}$ & $0.0 \pm 0.0 \mathrm{bc}$ & $0.0 \pm 0.0 \mathrm{f}$ & $0.4 \pm 0.0 \mathrm{e}$ \\
\hline \multicolumn{5}{|l|}{$\begin{array}{l}\text { Ltsp } \\
\text { PA2 }\end{array}$} \\
\hline Sc & $29.9 \pm 0.5 \mathrm{ab}$ & $0.1 \pm 0.0 \mathrm{abc}$ & $0.3 \pm 0.1 \mathrm{a}$ & $0.6 \pm 0.1 \mathrm{~d}$ \\
\hline LtSc & $26.4 \pm 0.3 c$ & $0.0 \pm 0.0 \mathrm{bc}$ & $0.2 \pm 0.0 \mathrm{~d}$ & $0.4 \pm 0.0 \mathrm{e}$ \\
\hline LtSp & $14.3 \pm 0.6 \mathrm{~d}$ & $0.0 \pm 0.0 \mathrm{bc}$ & $0.0 \pm 0.0 \mathrm{f}$ & $0.4 \pm 0.0 \mathrm{e}$ \\
\hline
\end{tabular}

${ }^{1}$ Comprises the content of malvidin-3-O-glucoside and its derivative malvidin-3-O-(6- $p$-coumaroylglucoside).

2 Comprises the content of identified polymeric pigments and unidentified peaks described in Table 4 . CAT: (+)-catechin, PB2: procyanidin B2, PC1: procyanidin C1, PA2: procyanidin A2.

Pyranoanthocyanins are shown in Table 3 in the vitisins and vinylphenolics groups. Regarding vitisin content, the pigment malvidin-3-O-glucoside acetaldehyde (Vitisin B) with molecular ion $[\mathrm{M}]^{+}$ $(m / z) 517$ and fragment ion with $(m / z) 355$ [33] was identified in all trials with no significant difference among them; nonetheless, the concentration of vitisin seems lower for sequential fermentation trials in treatment PA2 (Table 3). According to He et al. [34], the malvidin-3-O-glucoside-4-vinylphenol with molecular ion $[\mathrm{M}]^{+}(\mathrm{m} / \mathrm{z}) 609$ was the only vinylphenolic pigment identified in the trials where Sc was used as pure culture and sequential fermentation. The concentration in the pure culture trials ranged between 0.25 and $0.35 \mathrm{mg} / \mathrm{L}$, while the concentration in the trials with the fermentative strains Lt-Sc was between 0.18 and $0.22 \mathrm{mg} / \mathrm{L}$ (Table 3). The fermentative pair Lt-Sp did not produce vinylphenolics due to a lack in hydroxycinnamate decarboxylase activity; this enzymatic activity is associated with the selected Sc strain and is the result of the condensation of malvidin-3-O-glucoside and the decarboxylation of p-coumaric acid [5]. Although Suárez-Lepe and Morata [35] have reported hydroxycinnamate decarboxylase activity (HCDC) in non-Saccharomyces spp., there were no vinylphenolic pigments present in the wines produced with Lt-Sp yeasts in any of the treatments evaluated.

Polymeric pigments were formed during fermentation in all treatments and with all fermentative strains (Table 4). In treatment CAT, the isomers malvidin-3-O-glucoside-vinyl-catechin and malvidin-3-O-glucoside-vinyl-epicatechin with molecular ion [M] ${ }^{+}(\mathrm{m} / z) 805$ [36] were found in similar concentrations in trails fermented with Sc, while in sequential fermentations with Lt-Sp, the quantity of the epicatechin derivative was higher. The third oligomer found in this treatment was malvidin-3-O-( $p$-coumaroyl)-glucoside-8-ethyl-(epi) catechin with molecular ion $[\mathrm{M}]^{+}(\mathrm{m} / \mathrm{z})$ 955 and fragment ions with $(\mathrm{m} / \mathrm{z}) 803$ and 647 [34]; this structure corresponds to an ethyl-linked flavanol-anthocyanin dimer. PB2 treatment produced slightly higher concentrations of polymeric pigments with statistical significance for the fermentative strains Lt-Sp; the polymeric pigments identified in this treatment were malvidin-3-O-glucoside-epicatechin with molecular ion $[\mathrm{M}]^{+}(\mathrm{m} / z)$ 781 and fragment ion $(\mathrm{m} / \mathrm{z}) 619$, malvidin-3-O-glucoside-4-ethyl-epicatechin with molecular ion $[\mathrm{M}]^{+}(\mathrm{m} / \mathrm{z}) 809$, malvidin-3-O-glucoside-4-vinyl-epicatechin with molecular ion [M] $]^{+}(\mathrm{m} / z) 805$ and malvidin-3-O-glucoside-4-vinyl-diepicatechin with molecular ion [M] ${ }^{+}(m / z) 931$ [34]. The latter three pigments correspond to a flavanyl-pyranoanthocyanin structure, and the last pigment may correspond to the condensation of a malvidin unit with procyanidin B2, a trimer that is abundant in trials using 
the Sc strain in pure culture fermentation. The maximum absorption wavelength of these polymeric pigments was between $530 \mathrm{~nm}$ and $540 \mathrm{~nm}$.

Table 4. Pigments identified with HPLC-DAD-ESI/MS with DAD signal at 525nm.

\begin{tabular}{|c|c|c|c|c|c|}
\hline Compound & $t_{R}(\min )$ & {$[\mathrm{M}]^{+} m / z$} & Fragment $m / z$ & $\lambda_{\text {max-vis }}(\mathrm{nm})$ & Reference \\
\hline Malvidin-3-O-glucoside-epicatechin & 12.9 & 781 & 619 & 530 & [34] \\
\hline Unidentified Peak 1 & 13.4 & 679 & - & 514 & \\
\hline Malvidin-3-O-glucoside-4-vinyl-diepicatechin & 13.9 & 931 & - & 533 & [32] \\
\hline Malvidin-3-O-glucoside-ethyl-epicatechin & 14.2 & 809 & - & 538 & [34] \\
\hline Unidentified Peak 2 & 14.3 & 995 & 782 & 538 & \\
\hline Malvidin-3-O-(6-p-coumaroylglucoside)-8-ethyl-(epi)catechin & 14.5 & 954 & 852 & 520 & [34] \\
\hline Malvidin-3-O-glucoside-8-ethyl-epicatechin & 14.6 & 809 & 643 & 542 & [32] \\
\hline Malvidin-3-O-glucoside-4-vinyl-epicatechin & 14.9 & 805 & 331 & 540 & [36] \\
\hline Malvidin-3-O-glucoside-8-ethyl-catechin & 15.3 & 809 & 643 & 538 & [34] \\
\hline Diepicatechin-malvidin-3-O-glucoside & 16.2 & 1069 & 619 & 506 & [34] \\
\hline Unidentified Peak 3 & 17.3 & 829 & 691 & 512 & \\
\hline
\end{tabular}

$\left(\mathrm{t}_{\mathrm{R}}\right)$ retention time; $\left([\mathrm{M}]^{+}\right)$molecular ion; $(\lambda)$ maximum absorption wavelength.

Under the PC1treatment, three dimers and a trimer were identified: the dimers were the isomers malvidin-3-O-glucoside-8-ethyl-catechin and malvidin-3-O-glucoside-8-ethyl-epicatechin with molecular ion $[\mathrm{M}]^{+}(\mathrm{m} / \mathrm{z}) 805$ [34,36], and molecular structure flavanol-anthocyanin ethyl linked and the non-acetaldehyde mediated malvidin-3-O-glucoside-(epi) catechin with molecular ion $[\mathrm{M}]^{+}(\mathrm{m} / \mathrm{z}) 781$ and fragment ion $(\mathrm{m} / \mathrm{z}) 619$ [34]; the trimer found, with a slightly higher concentration in trials with strains Lt-Sp, was the malvidin-3-O-glucoside-4-vinyl-diepicatechin with molecular ion $[\mathrm{M}]^{+}(\mathrm{m} / z) 931$ [32]. There were no pigments identified from the direct condensation of procyanidin C1 (trimer) with malvidin-3-O-glucoside. The fourth treatment, PA2, produced the least concentration of oligomeric pigments, especially the fermentative strain Sc in pure culture fermentation with $0.09 \pm 0.01 \mathrm{mg} / \mathrm{L}$. The polymeric pigments found in this treatment were malvidin-3-O-glucoside-epicatechin with molecular ion $[\mathrm{M}]^{+}(\mathrm{m} / \mathrm{z}) 781$ and fragment ion $(\mathrm{m} / \mathrm{z}) 619$, the flavanol pyranoanthocyanin dimer malvidin-3-O-glucoside-4-vinyl-epicatechin with molecular ion $[\mathrm{M}]^{+}(\mathrm{m} / z) 805$ and flavanol pyranoanthocyanin trimer malvidin-3-O-glucoside-4-vinyl-diepicatechin with molecular ion [M] ${ }^{+}(\mathrm{m} / z) 931$ [32].

The direct condensation of the flavanol-anthocyanin dimers occurred at slower and lower yielding rates [37] than for the polymeric pigments formed when acetaldehyde was present. In this way, Dallas, Ricardo-da-Silva, and Laureano [38] have also documented the direct condensation of procyanidin B2 with malvidin-3-O-glucoside in the absence of acetaldehyde. Most of the polymeric pigments identified in this experimental design were mediated by acetaldehyde. The oligomer formation was not restrictive to having one moiety of anthocyanin and another of flavanol; two flavanol units may also condense in the presence of acetaldehyde and the anthocyanin may even be in hemiacetal form; from these polymeric pigments formed, the ethyl-flavanol oligomers are less stable [12]. The co-pigmentation equilibrium phenomena may increase the colour of wine, displacing some of the colourless anthocyanins into coloured oligomers [13]. Three peaks were labelled as unidentified, as the molecular weight does not correlate to the expected molecular structures. Unidentified peaks 1 and 3 occurred in treatments CAT and PB2, while all three were present in treatments PC1 and PA2.

The contribution of the yeast strains and the different treatments to the evolution and stability of the pigments can be seen in a PCA chart in Figure 2. Two principal components explain the $84.7 \%$ variability of the experimental design. Component 1 had positive contributions from malvidin-3-O-gucoside, total pigments and vinyphenolics while Component 2 had positive contributions from polymeric pigments and vitisins. In this way, there are three different clusters observed with respect to Component 1 , where those trials with more pigments are located to the right side of the chart and correspond to pure culture fermentation with Sc, while trials with the least concentration are located to the left; this behaviour was observed by Escott et al. [11] for other non-Saccharomyces spp. including T. delbrueckii and M. pulcherrima. Regarding Component 2, the contribution of the treatments to the pigment formation can be seen for each fermentative media; the CAT treatment produced the highest concentration of oligomeric pigments in all three clusters, 
as previously observed in the results of the HPLC-DAD-ESI/MS analysis, followed by PB2 treatment for trials with Lt-Sp (Figure 2-left side) and by the PC1 treatment for trials Sc and Lt-Sc.

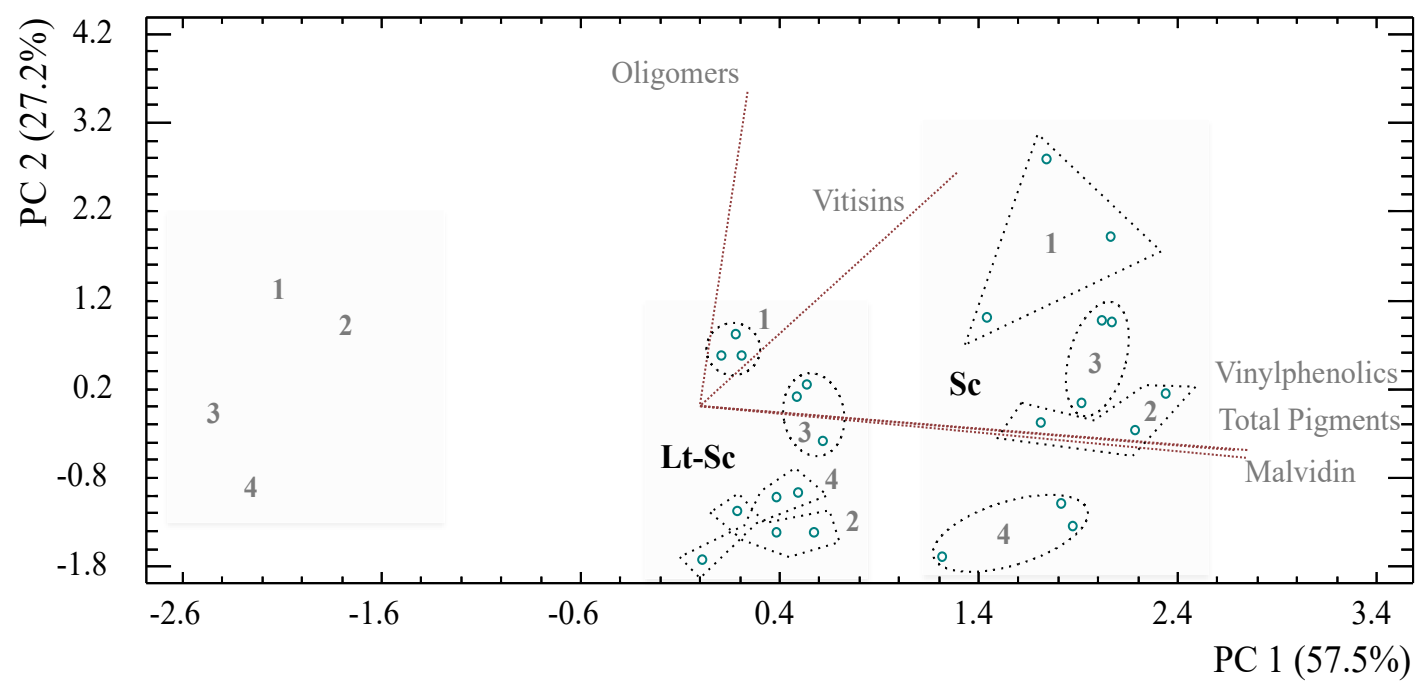

Figure 2. Principal Component Analysis (PCA) for pigments determination in experimental trials. The clusters identified correspond to the fermentative yeasts used (block font). The numbers refer to each of the four treatments assessed: (1) CAT; (2) PB2; (3) PC1, and; (4) PA2.

\subsection{Colour and Polyphenol Assessment}

Spectrophotometry, in particular UV-Vis, was used to determine the colour parameters as well as polyphenols due to the ability of anthocyanins and flavanols to absorb at different wavelengths in function of their molecular structure. Table 5 summarizes all parameters obtained from the absorption at wavelengths in both the UV and the visible spectra. The colour intensity and hue showed greater values for the trials fermented with the pair Lt-Sp for all treatments; there was also a slight increase in the values of these parameters in the following order of fermentative yeasts $\mathrm{Sc}<\mathrm{Lt}-\mathrm{Sc}<\mathrm{Lt}-\mathrm{Sp}$. The anthocyanin ionization degree (Table 5) was also higher for the fermentative pair Lt-Sp, meaning that the fraction of pigments with flavylium form was higher, and therefore the observed colour may be more intense. The concentration of pigments measured with this technique was inverse to the colour intensity, meaning that the wines fermented with Sc had a larger amount of pigments at the end of fermentation, and, as found with high performance liquid chromatography coupled with mass spectrometer (HPLC-DAD-ESI/MS), the concentration of malvidin-3-O-glucoside was higher in these wines followed by the wines where Lt-Sc was used. The trials with the lowest concentration of polymeric pigments and total pigments corresponded to those fermented with Sp. The trend of these values differed from that observed with HPLC-DAD-ESI/MS, making evident the larger measuring range of the UV-Vis technique. 
Table 5. Results from UV-Vis determination of colour parameters and polyphenols. The statistical analysis is given by parameter (columns) and the difference in letters indicates significant statistical difference (LSD method with 95\% confidence level). Means $\pm \operatorname{STD}(n=3)$.

\begin{tabular}{|c|c|c|c|c|c|c|c|c|}
\hline Treatment & $\begin{array}{c}\mathrm{I} \\
\mathrm{AU}\end{array}$ & $\mathbf{N}$ & $\alpha \%$ & $\begin{array}{l}\text { TPI } \\
\text { AU }\end{array}$ & ChA & $\begin{array}{l}\text { PI } \\
\%\end{array}$ & $\begin{array}{l}\text { PP } \\
\text { AU }\end{array}$ & $\begin{array}{l}\text { TP } \\
\text { AU }\end{array}$ \\
\hline CAT & & & & & & & & \\
\hline $\mathrm{Sc}$ & $0.78 \pm 0.0 \mathrm{bc}$ & $1.59 \pm 0.0 \mathrm{c}$ & $17.76 \pm 0.8 \mathrm{bc}$ & $13.81 \pm 0.1 \mathrm{~b}$ & $0.13 \pm 0.0 b c$ & $12.77 \pm 0.6 \mathrm{de}$ & $0.13 \pm 0.0 \mathrm{bc}$ & $1.03 \pm 0.1 \mathrm{a}$ \\
\hline Lt-Sc & $0.80 \pm 0.0 \mathrm{ab}$ & $1.65 \pm 0.0 c$ & $30.84 \pm 1.8 \mathrm{a}$ & $13.41 \pm 0.1 \mathrm{~b}$ & $0.23 \pm 0.0 \mathrm{a}$ & $23.12 \pm 0.6 \mathrm{ab}$ & $0.15 \pm 0.0 \mathrm{a}$ & $0.66 \pm 0.0 \mathrm{~d}$ \\
\hline $\begin{array}{l}\text { Lt-Sp } \\
\text { PB2 }\end{array}$ & $0.82 \pm 0.0 \mathrm{ab}$ & $2.25 \pm 0.0 \mathrm{ab}$ & $23.53 \pm 3.6 \mathrm{~b}$ & $14.77 \pm 0.1 \mathrm{a}$ & $0.25 \pm 0.0 \mathrm{a}$ & $25.27 \pm 2.2 \mathrm{a}$ & $0.15 \pm 0.0 \mathrm{a}$ & $0.59 \pm 0.0 \mathrm{~d}$ \\
\hline $\mathrm{Sc}$ & $0.71 \pm 0.1 \mathrm{~d}$ & $1.59 \pm 0.0 \mathrm{c}$ & $16.39 \pm 0.2 c$ & $13.70 \pm 0.5 \mathrm{~b}$ & $0.12 \pm 0.0 \mathrm{c}$ & $11.80 \pm 0.7 \mathrm{e}$ & $0.12 \pm 0.0 \mathrm{c}$ & $1.02 \pm 0.1 \mathrm{ab}$ \\
\hline Lt-Sc & $81 \pm 0.0 \mathrm{ab}$ & $1.64 \pm 0.0 \mathrm{c}$ & $22.86 \pm 2.2 \mathrm{bc}$ & $13.39 \pm 0.0 \mathrm{~b}$ & $0.19 \pm 0.0 \mathrm{~b}$ & $19.17 \pm 1.1 \mathrm{bc}$ & $0.16 \pm 0.0 \mathrm{a}$ & $0.82 \pm 0.1 \mathrm{c}$ \\
\hline $\begin{array}{l}\text { Lt-Sp } \\
P C 1\end{array}$ & $0.84 \pm 0.0 \mathrm{a}$ & $2.17 \pm 0.0 \mathrm{~b}$ & $22.68 \pm 4.2 \mathrm{bc}$ & $15.04 \pm 0.2 \mathrm{a}$ & $0.25 \pm 0.0 \mathrm{a}$ & $24.61 \pm 1.3 \mathrm{a}$ & $0.16 \pm 0.0 \mathrm{a}$ & $0.64+0.1 \mathrm{~d}$ \\
\hline $\mathrm{Sc}$ & $0.74 \pm 0.0 \mathrm{~cd}$ & $1.64 \pm 0.0 \mathrm{c}$ & $18.49 \pm 1.6 \mathrm{bc}$ & $13.61 \pm 0.1 \mathrm{~b}$ & $0.13 \pm 0.0 \mathrm{bc}$ & $12.84 \pm 0.6 \mathrm{de}$ & $0.12 \pm 0.0 \mathrm{c}$ & $0.95 \pm 0.1 \mathrm{~b}$ \\
\hline Lt-Sc & $0.80 \pm 0.0 \mathrm{ab}$ & $1.65 \pm 0.0 \mathrm{c}$ & $22.48 \pm 1.2 \mathrm{bc}$ & $13.36 \pm 0.1 \mathrm{~b}$ & $0.18 \pm 0.0 \mathrm{~b}$ & $18.44 \pm 0.4 \mathrm{c}$ & $0.15 \pm 0.0 \mathrm{a}$ & $0.82 \pm 0.0 \mathrm{c}$ \\
\hline $\begin{array}{l}\text { Lt-Sp } \\
P A 2\end{array}$ & $0.84 \pm 0.0 \mathrm{a}$ & $2.20 \pm 0.1 \mathrm{ab}$ & $24.53 \pm 2.9 \mathrm{ab}$ & $14.64 \pm 0.3 \mathrm{a}$ & $0.27 \pm 0.0 \mathrm{a}$ & $26.70 \pm 2.7 \mathrm{a}$ & $0.16 \pm 0.0 \mathrm{a}$ & $0.59 \pm 0.0 \mathrm{~d}$ \\
\hline Sc & $75 \pm 0.0 \mathrm{~cd}$ & $1.64 \pm 0.0 \mathrm{c}$ & $20.60 \pm 1.2 b c$ & $13.81 \pm 0.1 \mathrm{~b}$ & $0.16 \pm 0.0 \mathrm{ab}$ & $15.84 \pm 0.7 \mathrm{~cd}$ & $0.14 \pm 0.0 \mathrm{~b}$ & $0.85 \pm 0.0 \mathrm{c}$ \\
\hline Lt-Sc & $0.82 \pm 0.0 \mathrm{ab}$ & $1.66 \pm 0.0 \mathrm{c}$ & $23.22 \pm 2.5 b$ & $13.38 \pm 0.2 b$ & $0.19 \pm 0.0 \mathrm{~b}$ & $19.05 \pm 1.9 c$ & $0.16 \pm 0.0 \mathrm{a}$ & $0.82 \pm 0.1 \mathrm{c}$ \\
\hline Lt-Sp & $0.84 \pm 0.0 \mathrm{a}$ & $2.26 \pm 0.0 \mathrm{a}$ & $21.77 \pm 2.0 \mathrm{bc}$ & $14.86 \pm 0.2 \mathrm{a}$ & $0.25 \pm 0.0 \mathrm{a}$ & $25.31 \pm 0.9 \mathrm{a}$ & $0.16 \pm 0.0 \mathrm{a}$ & $0.62 \pm 0.0 \mathrm{~d}$ \\
\hline
\end{tabular}

I: Colour intensity; N: Hue (N); $\alpha$ : anthocyanin ionization degree; TPI: total polyphenols index; ChA: chemical age;

PI: polymerization index; PP: polymerized pigments; TP: total pigments.

With regard to chemical age (ChA) and polymerization index (PI) (Table 5), the values were higher for the fermentative pair Lt-Sp as observed for hue $(\mathrm{N})$, mainly due to the fact that the ratio of oligomeric pigments to total pigments was higher for these trials even though the concentration of total pigments was shorter, as found by Chen et al. [39]. According to these authors, the concentration of monomeric and total pigments decreased when using $\mathrm{Sp}$ as the fermentative yeast, but the fraction of oligomeric pigments increased. The fact of having more oligomeric pigments, and therefore higher concentrations of $\mathrm{ChA}$, suggests an increase in compounds with absorption at shorter wavelengths, similar to those pigments found in aged wines. The values of the total polyphenols index (TPI) were statistically different for the trials Lt-Sp, with a slightly higher numerical difference from the other trials.

A Pearson correlation plot for the pigments and colour parameters is shown in Table 6. The plot confirms the results previously discussed. For the pigments and colour parameters, the correlation indicates a strong and very strong negative relationship between malvidin and vinylphenolics with most indexes (I, N, TPI, ChA, PI and PP), while the relationship was very strongly positive between these pigments and the total pigments index (TP). For vitisin and oligomers, the correlation with all indexes, except for polymeric pigments, was not significant at $5 \%$; the correlation between these pigments and the polymeric pigment index (PP) was strongly positive. It can be observed that the higher the amount of malvidin and vinylphenolics observed at the end of the fermentation, the lower the index obtained.

Table 6. Pearson correlation plot for pigments and colour indexes. $X$ indicates values not significant at $5 \%$. $P$-values below 0.05 indicate statistically significant non-zero correlations. $R$ values $=+0.7$ or higher indicate very strong positive relationship while, $R$ values $=-0.7$ or higher indicate very strong negative relationship.

\begin{tabular}{rcccccccccccc}
\hline & Malvidin & Vitisin & Vinyphenolics & OligomersI & $\mathbf{N}$ & $\alpha$ & TPI & ChA & PI & PP & TP \\
\hline Malvidin & & $\mathrm{X}$ & 0.930 & $\mathrm{X}$ & -0.799 & -0.979 & $\mathrm{X}$ & -0.890 & -0.906 & -0.900 & -0.660 & 0.872 \\
Vitisin & $\mathrm{X}$ & & $\mathrm{X}$ & 0.704 & $\mathrm{X}$ & $\mathrm{X}$ & $\mathrm{X}$ & $\mathrm{X}$ & $\mathrm{X}$ & $\mathrm{X}$ & -0.633 & $\mathrm{X}$ \\
Vinyphenolics & 0.930 & $\mathrm{X}$ & & $\mathrm{X}$ & -0.848 & -0.920 & $\mathrm{X}$ & -0.783 & -0.901 & -0.898 & -0.696 & 0.889 \\
Oligomers & $\mathrm{X}$ & 0.704 & $\mathrm{X}$ & & $\mathrm{X}$ & $\mathrm{X}$ & $\mathrm{X}$ & $\mathrm{X}$ & $\mathrm{X}$ & $\mathrm{X}$ & -0.645 & $\mathrm{X}$ \\
$\mathrm{I}$ & -0.799 & $\mathrm{X}$ & -0.848 & $\mathrm{X}$ & & 0.701 & 0.602 & $\mathrm{X}$ & 0.878 & 0.882 & 0.920 & -0.816 \\
$\mathbf{N}$ & -0.979 & $\mathrm{X}$ & -0.920 & $\mathrm{X}$ & 0.701 & & $\mathrm{X}$ & 0.939 & 0.841 & 0.834 & $\mathrm{X}$ & -0.826 \\
$\mathbf{\alpha}$ & $\mathrm{X}$ & $\mathrm{X}$ & $\mathrm{X}$ & $\mathrm{X}$ & 0.602 & $\mathrm{X}$ & & $\mathrm{X}$ & 0.711 & 0.720 & 0.667 & -0.733 \\
TPI & -0.890 & $\mathrm{X}$ & -0.783 & $\mathrm{X}$ & $\mathrm{X}$ & 0.939 & $\mathrm{X}$ & & 0.672 & 0.654 & $\mathrm{X}$ & -0.649 \\
ChA & -0.906 & $\mathrm{X}$ & -0.901 & $\mathrm{X}$ & 0.878 & 0.841 & 0.711 & 0.672 & & 0.999 & 0.833 & -0.985 \\
PI & -0.900 & $\mathrm{X}$ & -0.898 & $\mathrm{X}$ & 0.882 & 0.834 & 0.720 & 0.654 & 0.999 & & 0.840 & -0.987 \\
PP & -0.660 & -0.633 & -0.696 & -0.645 & 0.920 & $\mathrm{X}$ & 0.667 & $\mathrm{X}$ & 0.833 & 0.840 & & -0.788 \\
TP & 0.872 & $\mathrm{X}$ & 0.889 & $\mathrm{X}$ & -0.816 & -0.826 & -0.733 & -0.649 & -0.985 & -0.987 & -0.788 & \\
\hline
\end{tabular}

I: Colour intensity; N: Hue (N); $\alpha$ : anthocyanin ionization degree; TPI: total polyphenols indeX; ChA; chemical age; PI: polymerization indeX; PP: polymerized pigments; TP: total pigments. 


\section{Materials and Methods}

\subsection{Yeast Strains and Yeast Population Growth}

The species Lachancea thermotolerans (Lt) strain CHKt 421 (Viniflora ${ }^{\circledR}, \mathrm{Chr}-H a n s e n$ ) was used in sequential fermentation with the Saccharomyces cerevisiae (Sc) strain 7VA (EnotecUPM, Madrid, Spain) and the Schizosaccharomyces pombe (Sp) strain 938 (IFI, SCIC, Madrid, Spain). A pure-culture fermentation with the yeast $S$. cerevisiae was used as a control trial. All yeasts were firstly grown in stripe, and later in liquid YPD media (yeast eXtract, peptone and deXtrose) before fermentation for $48 \mathrm{~h}$ at $25{ }^{\circ} \mathrm{C}$ to reach a population in the pre-inoculum of $1.00 \times 10^{7}$ and $1.06 \times 10^{7} \mathrm{CFU} / \mathrm{mL}$ by count plates for the species $\mathrm{Lt}$ and Sc, respectively. The sequential fermentations were performed using the Sc and Sp species, grown in the same liquid YPD media at $25^{\circ} \mathrm{C}$ for $48 \mathrm{~h}$ to reach a population of 6.01 $\times 10^{6}$ and $9.80 \times 10^{5} \mathrm{CFU} / \mathrm{mL}$ in the respective pre-inoculums. Obtaining $500 \mu \mathrm{L}$ from the fermenter flasks at days 3, 7, 9 and 13 followed the yeast growing kinetics; the sequential fermentation was done at day 7. The yeast populations were measured by plate counting. The liquid YPD growing media was prepared with $1 \%$ yeast eXtract (Laboratorios Conda; Madrid, Spain), $2 \%$ bacteriological peptone (Laboratorios Conda; Madrid, Spain), and 2\% D (+)-glucose anhydrous (Panreac Química; Barcelona, Spain); the liquid YPD media was sterilized in an autoclave at $120^{\circ} \mathrm{C}$ for $15 \mathrm{~min}$. The colonies were determined by plate counting using YPD agar and second medium with lysine agar where S. cerevisiae was unable to grow. The growth media for plate counting was performed according to Loira et al. [7] for YPD agar at $25{ }^{\circ} \mathrm{C}$ for 2 days and at $28{ }^{\circ} \mathrm{C}$ for 2 days for lysine phosphate medium plates for non-Saccharomyces spp.

\subsection{Corrected Must for Winemaking}

White concentrated must, Vitis vinifera L. cv. Airén from the 2016 vintage, was used to prepare the corrected must base. The must, following correction, had a density of 1100 and a pH of 3.4 after adding $0.79 \mathrm{~g} / \mathrm{L}$ of L (+)-tartaric acid (Panreac Química; Barcelona, Spain). The alcohol potential for this must was eXpected to be $13.8 \% v / v\left(23.4^{\circ} \mathrm{BriX}\right)$. The must was sterilized in an autoclave at $100{ }^{\circ} \mathrm{C}$ for $1 \mathrm{~min}$ in $3 \mathrm{~L}$ containers and included a previous addition of malvidin-3-O-glucoside and flavanols. Microbiological control analysis showed no presence of either yeast colonies $\left(10^{\circ}\right.$ in $\left.100 \mathrm{~mL}\right)$ or mesophilic bacteria in the must prior to the inoculation of the yeasts $\left(\mathrm{t}_{0}\right)$.

Malvidin-3-O-glucoside (CAS: 643-84-5) was added to the sterile must to obtain an initial concentration of $40 \mathrm{mg} / \mathrm{L}$; it was divided into $4250 \mathrm{~mL}$ flasks in order to prepare the four different must media. The four must media treatments were named after the flavanols used: (+)-catechin (CAT), procyanidin B2 (PB2), procyanidin C1 (PC1) and procyanidin A2 (PA2). The flavanols (+)-catechin (CAS: 154-23-4 and purity of 99\%), procyanidin B2 (CAS: 29106-49-8 and purity of 90\%), procyanidin C1 (CAS: 37064-30-5 and purity of $>95 \%$ ) and procyanidin A2 (CAS:41743-41-3) (Cymit Química S.L., Barcelona. Spain) were used at a concentration of $20 \mathrm{mg} / \mathrm{L}$.

Each of the four model solutions were transferred into $60 \mathrm{~mL}$ microfermenters after which $750 \mu \mathrm{L}$ of inoculum of either Sc (trial 1) or Lt (trials 2 and 3) yeast strains were added in triplicate. Microfermenters were sealed with Müller valves and placed at a constant $25^{\circ} \mathrm{C}$ after being weighed. After day 7, a second inoculum of $750 \mu \mathrm{L}$ was added to the Sc yeasts (trials 1 and 2) or Sp (trial 3) to finish fermenting residual sugars and to achieve maXimum fermentative power. Fermentation kinetics were followed until a stable weight was reached. Fermentations spanned 14 days for pure-culture fermentation and up to 21 days for sequential fermentation.

In this way, the eXperiment was comprised of the following miX design: four model solution treatments fermented with Sc as a control (trial 1); a second trial that comprised the use of Lt in sequential fermentation with Sc, and; a third trial had Lt in sequential fermentation with Sp. This resulted in 12 different fermentation trials by triplicate. As an eXample, Figure 3 shows the first three fermentation trials corresponding to the CAT treatment. 


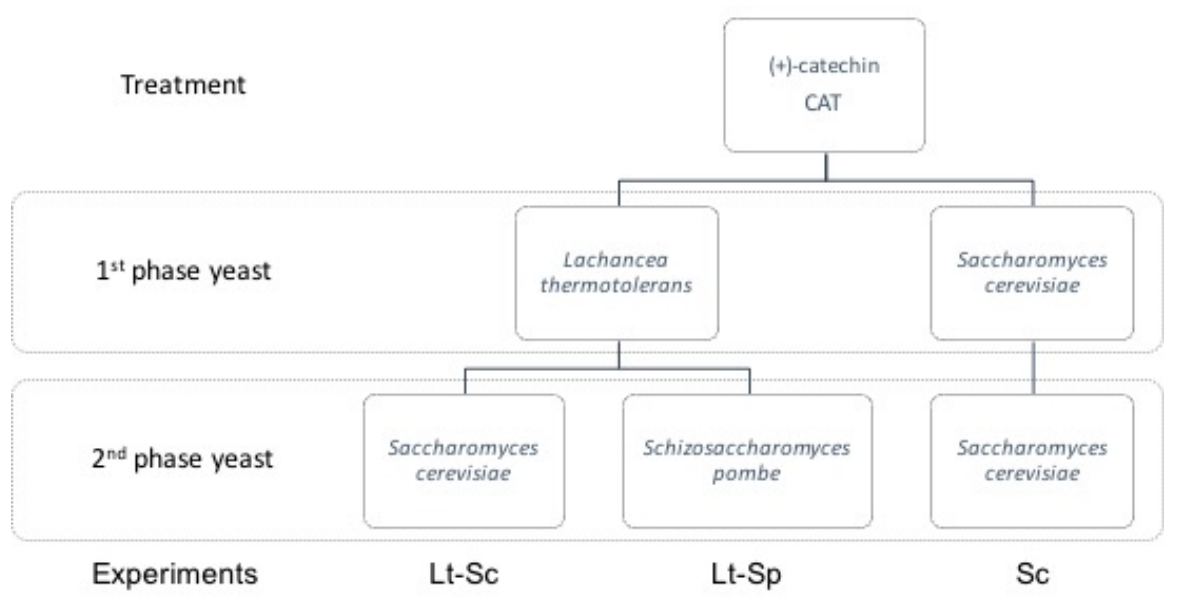

Figure 3. EXperimental design for CAT treatment. Three different trials named Lt-Sc, Lt-Sp and Sc resulted from the combination of 1st and 2nd phase yeast. The other treatments assessed (PB2, PC1, and PA2) followed the same design.

\subsection{Main Wine Parameters}

The main parameters such as residual sugars, malic acid, lactic acid, total acidity, volatile acidity and $\mathrm{pH}$ values were measured by Fourier transform infrared spectroscopy (FTIR) with the OenoFoss ${ }^{\mathrm{TM}}$ equipment (FOSS Iberia, Barcelona, Spain) to characterize wines after fermentation. Pyruvic acid production during fermentation was followed up with an enzymatic analysis by spectrophotometric determination with the use of the Analyzer Y15 (Biosystems, Barcelona, Spain) at times 0, 3, 7, 9 and 13 days and in triplicate. The enzymatic reagent used for the analysis was the 12826-Pyruvic acid (Biosystems, Barcelona, Spain), containing D-Lactate dehydrogenase.

\subsection{Fermentative Volatile Compounds}

A gas chromatography with flame ionization detector (GC-FID) was used for the determination of volatile compounds. The chromatograph used was an Agilent Technologies ${ }^{\mathrm{TM}} 6850$ (Palo Alto, CA, USA) with a DB-624 column $(60 \mathrm{~m} \times 250 \mu \mathrm{m} \times 1.4 \mu \mathrm{m})$. The injector temperature was $250{ }^{\circ} \mathrm{C}$ and the detector temperature was set to $300{ }^{\circ} \mathrm{C}$. The temperature went from a steady $40{ }^{\circ} \mathrm{C}$ for $5 \mathrm{~min}$ to ${ }^{\circ} \mathrm{C}$ at intervals of $10{ }^{\circ} \mathrm{C} / \mathrm{min}$. This temperature was maintained for $5 \mathrm{~min}$. Hydrogen was used as a carrier gas at a $2.2 \mathrm{~L} / \mathrm{min}$ flow with a split ratio of 1:10. The identification and quantification of volatile compounds were performed with $100 \mu \mathrm{L}$ of 4-methyl-2-pentanol $(500 \mathrm{mg} / \mathrm{L})$ used as an internal standard [40]. The method comprised the calibration of the column with the following compounds as eXternal standards: acetaldehyde, methanol, 1-propanol, 1-butanol, 2-butanol, isobutanol, 2-methyl-1-butanol, 3-methyl-1-butanol, 2-phenylethyl acetate, 2-phenylethyl alcohol, diacetyl, ethyl acetate, isoamyl acetate, isobutyl acetate, ethyl butyrate, ethyl lactate and heXanol. For acetaldehyde determination, the calibration $R^{2}$ was 0.99973 for concentrations between 5 and $500 \mathrm{mg} / \mathrm{L}$. The detection limit was $0.1 \mathrm{mg} / \mathrm{L}$.

\subsection{Pigment Characterization}

The use of an HPLC with a diode array detector and electro spray ionization coupled with a mass spectroscopy (DAD-ESI/MS) was used to identify and characterize malvidin-3-O-glucoside, vitisin $\mathrm{B}$, malvidin-3-O-glucoside acyl derivatives and polymeric pigments with malvidin-3-O-glucoside; the HPLC was a Agilent Technologies ${ }^{\mathrm{TM}} 1100$ (Palo Alto, CA, USA) chromatograph with a column RP KineteX C18 100^ $(100 \times 4.6 \mathrm{~mm} ; 2.6 \mu \mathrm{m})$ (PhenomeneX, Torrance, CA, USA). The eluents used comprised eluent A (water/formic acid 95:5 $v / v$ ) and eluent B (methanol/formic acid 95:5 $v / v$ ), with the following gradient of eluent B $(0.8 \mathrm{~mL} / \mathrm{min})$ : from $20 \%$ to $50 \%$ from $0 \mathrm{~min}$ to $27 \mathrm{~min} ; 50 \%$ from $27 \mathrm{~min}$ to $28 \mathrm{~min}$, and finally, from $50 \%$ to $20 \%$ from $28 \mathrm{~min}$ to $29 \mathrm{~min}$ until a steady state was 
reached. According to Loira et al. [7], malvidin-3-O-glucoside has been used as an eXternal standard at a wavelength of $525 \mathrm{~nm}$ for the quantification of all pigments, while the identification was carried out with mass spectrometry positive scanning from 100 to $1500 \mathrm{~m} / \mathrm{z}$ from $0 \mathrm{~min}$ to $23 \mathrm{~min}$. The detection limit was set to $0.1 \mathrm{mg} / \mathrm{L}$ [41].

\subsection{Colour Assessment, Total Anthocyanins and Total Phenolics}

The colour intensity (I) as well as colour shade $(\mathrm{N})$, anthocyanin ionization degree $(\alpha)$, total phenolics (TPI), chemical age (ChA), polymerization indeX (PI), polymerized pigments (PP) and total pigments (TP) of red wine samples were determined through the use of a UV-visible spectrometer Unicamp $^{\mathrm{TM}}$ UV4 (Algés, Lisbon, Portugal) using $1 \mathrm{~mm}$ and $1 \mathrm{~cm}$ path length cuvettes following the Somers and Evans [42] methodology. Colour intensity (I) is eXpressed as the sum of absorbance at maXimal wavelengths A420 nm, A520 nm and A620 nm; colour hue (N) is obtained from the ratio A420 $\mathrm{nm} / \mathrm{A} 520 \mathrm{~nm}$; anthocyanin ionization degree $(\alpha)$ with the formula [A520 nm - A520 nm $\mathrm{SO} 2 / \mathrm{A}_{52} \mathrm{HCl}_{\mathrm{HCl}}$ $-5 / 3$ A520 $\left.\mathrm{nm}_{\mathrm{SO} 2}\right] \times 100 \%$; total phenolics (TPI) is the indeX obtained from multiplying A280 $\mathrm{nm}$ $\times 10$ (dilution correction); chemical age (ChA) is eXpressed as the ratio of $\mathrm{A} 520 \mathrm{~nm}_{\mathrm{SO} 2} / \mathrm{A} 520 \mathrm{~nm}_{\mathrm{HCl}}$; polymerization indeX $(\mathrm{PI})$ obtained from $\mathrm{ChA} \times 100$; polymerized pigments $(\mathrm{PP})$ as the absorption A520 ${ }_{\mathrm{SO} 2}$, and; total pigments (TP) as the absorption $\mathrm{A} 520_{\mathrm{HCl}}$.

\subsection{Statistical Analysis}

Means and standard deviations were calculated and differences eXamined using ANOVA and the least significant difference (LSD) test. All calculations were made using the PC Statgraphics v.XI software (Graphics Software Systems, Rockville, MD, USA). Significance was set at $P<0.05$.

\section{Conclusions}

The use of (+)-catechin in musts produced a higher concentration of oligomeric pigments, most of which are linked to acetaldehyde. The use of both Saccharomyces cerevisiae and Schizosaccharomyces pombe in sequential fermentation increased the production of acetaldehyde and pyruvic acid toward the end of the fermentation process, making possible the formation of stable pigments during this stage. Therefore, the colour of wines is a result of the concentration of monomeric pigments and the oligomeric fraction formed during fermentation. The different treatments, meaning the addition of flavanols to musts before fermentation, did not seem to have an influence on the metabolic pathways for fermentative volatile production for samples with the same fermentative conditions; most of the differences in fermentative volatiles found in wines were related to the yeasts used for fermentation. Less 2,3-butanediol and more fruity esters were formed when using non-Saccharomyces yeasts. Not only the aromatic profile, but also the colour observed in the wines changed as a result of the nature of the fermentative strains used, some of which may have had higher pigment adsorption on their cell wall structure.

Author Contributions: Conceptualization, C.E. and A.M.; Data curation, C.E., J.M.R.-d.-S. and M.J.C.; Formal analysis, C.E. and A.M. ; Funding acquisition, A.M. and J.M.R.-d.-S.; Investigation, C.E.; Methodology, C.E.; Project administration, A.M. and J.A.S.-L.; Resources, A.M., J.M.R.-d.-S. and J.A.S.-L. ; Software, C.E.; Supervision, A.M., J.M.R.-d.-S. and J.A.S.-L.; Validation, A.M., J.M.R.-d.-S. and M.d.C.G.; Writing-original draft, C.E.; Writing-review \& editing, C.E., M.J.C. and M.d.C.G.

Funding: This body of research has been supported by Ministerio de Economía, Industria y Competitividad (MINECO-Spain) [grant number AGL2013-40503-R] and by Fundação para a Ciência e a Tecnologia (FCT-Portugal) [grant number UID/AGR/04129/2013].

Acknowledgments: The authors thank the Consejo Social at the Universidad Politécnica de Madrid (UPM) for their support as well as the Consejo Nacional de Ciencia y Tecnología (CONACYT-MéXico) for the pre-doctoral scholarship awarded. Special thanks to all personnel in the Laboratorio Ferreira Lapa at Instituto Superior de Agronomia (ISA) at the Universidade de Lisboa (ULisboa) in Lisbon, Portugal, in particular to Daniel Duarte and Diana Faria, and to the personnel at the Department of Chemistry and Food Technology in the ETSIAAB at the Technical University of Madrid (UPM) in Spain for all the support received. 
Conflicts of Interest: The authors declare no conflict of interest

Chemical Compounds Studied in This Article: Acetaldehyde (PubChem CID: 177); Malvidin-3-O-glucoside (PubChem CID: 443652); Pyruvic acid (PubChem CID: 1060); Vitisin A (PubChem CID: 16131430); Vitisin B (PubChem CID: 16138152); (+)-Catechin (PubChem CID: 73160); Procyanidin B2 (PubChem CID: 122738); Procyanidin C1 (PubChem CID: 169853); Procyanidin A2 (PubChem CID: 124025); Malvidin-3-O-glucoside-ethyl-catechin (PubChem CID: 71308233)

\begin{tabular}{ll}
\multicolumn{2}{l}{ Abbreviations } \\
Lt & Lachancea thermotolerans \\
Sc & Saccharomyces cerevisiae \\
Sp & Schizosaccharomyces pombe \\
CAT & (+)-catechin \\
PB2 & procyanidin B2 \\
PC1 & procyanidin C1 \\
PA2 & procyanidin A2 \\
I & colour Intensity \\
N & hue \\
ChA & chemical age \\
TPI & total polyphenols indeX \\
N & hue; ionization degree \\
PP & polymeric pigments \\
PI & polymerization indeX \\
CFU $/ m L$ & colony-forming unit per milliliter
\end{tabular}

\section{References}

1. Pérez-Lamela, C.; García-Falcón, M.S.; Simal-Gándara, J.; Orriols-Fernández, I. Influence of grape variety, vine system and enological treatments on the colour stability of young red wines. Food Chem. 2007, 101, 601-606. [CrossRef]

2. Oliva, J.; Azorín, P.; Cámara, M.A.; Barba, A.; Pardo, F. Incidencia de la adición de distintos tipos de taninos enológicos en el colour de vinos tintos de Monastrell. Aliment. Equipos Tecnol. 2001, 20, 87-92.

3. Salinas, M.R.; Garijo, J.; Pardo, F.; Zalacaín, A.; Alonso, G.L. Colour, polyphenol, and aroma compounds in rosé wines after prefermentative maceration and enzymatic treatments. Am. J. Enol. Vitic. 2003, 54, 195-202.

4. Morata, A.; Calderón, F.; González, M.C.; Gómez-Cordovés, M.C.; Suárez, J.A. Formation of the highly stable pyranoanthocyanins (vitisins A and B) in red wines by the addition of pyruvic acid and acetaldehyde. Food Chem. 2007, 100, 1144-1152. [CrossRef]

5. Morata, A.; Gómez-Cordovés, M.C.; Calderón, F.; Suárez, J.A. Effects of pH, temperature and $\mathrm{SO}_{2}$ on the formation of pyranoanthcoyanins during red wine fermentation with two species of Saccharomyces. Int. J. Food Microbiol. 2006, 106, 123-129. [CrossRef] [PubMed]

6. Mateus, N.; Silva, A.M.S.; Santos-Buelga, C.; Rivas-Gonzalo, J.C.; de Freitas, V. Identification of anthocyanin-flavanol pigments in red wines by NMR and mass spectrometry. J. Agric. Food. Chem. 2002, 50, 2110-2116. [CrossRef] [PubMed]

7. Loira, I.; Vejarano, R.; Bañuelos, M.A.; Morata, A.; Tesfaye, W.; Uthurry, C.; Villa, A.; Cintora, I.; Suárez-Lepe, J.A. Influence of sequential fermentation with Torulaspora delbrueckii and Saccharomyces cerevisiae on wine quality. LWT-Food Sci. Technol. 2014, 59, 915-922. [CrossRef]

8. Morata, A.; Benito, S.; Loira, I.; Palomero, F.; González, M.C.; Suárez-Lepe, J.A. Formation of pyranoanthocyanins by Schizosaccharomyces pombe during the fermentation of red must. Int. J. Food Microbiol. 2012, 159, 47-53. [CrossRef] [PubMed]

9. Sadineni, V.; Kondapalli, N.; Obulam, V.S.R. Effect of co-fermentation with Saccharomyces cerevisiae and Torulaspora delbrueckii or Metschnikowia pulcherrima on the aroma and sensory properties of mango wine. Ann. Microbiol. 2012, 62, 1353-1360. [CrossRef]

10. Suárez-Lepe, J.A.; Palomero, F.; Benito, S.; Calderón, F.; Morata, A. Oenological versatility of Schizosaccharomyces spp. Eur. Food Res. Technol. 2012, 235, 375-383. [CrossRef] 
11. Escott, C.; del Fresno, J.M.; Loira, I.; Morata, A.; Tesfaye, W.; González, M.C.; Suárez-Lepe, J.A. Formation of polymeric pigments in red wine through sequential fermentation of flavanol-enriched musts with non-Saccharomyces yeasts. Food Chem. 2018, 239, 975-983. [CrossRef] [PubMed]

12. Es-Safi, N.; Cheynier, V. Flavanols and anthocyanins as potent compounds in the formation of new pigments during storage and aging of red wine. ACS Symp. Ser. 2004, 886, 143-159.

13. Darias-Martín, J.; Carrillo, M.; Díaz, E.; Boulton, R.B. Enhancement of red wine colour by pre-fermentation addition of copigments. Food Chem. 2001, 73, 217-220. [CrossRef]

14. Salas, E.; Atanasova, V.; Poncet-Legrand, C.; Meudec, E.; Mazauric, J.P.; Cheynier, V. Demonstration of the Ocurrence of Flavanol-Anthocyanin Adducts in wine and in Model Solutions. Anal. Chim. Acta 2004, 513, 325-332. [CrossRef]

15. Cheynier, V.; Dueñas-Paton, M.; Salas, E.; Maury, C.; Souquet, J.M.; Sarni-Manchado, P.; Fulcrand, H. Structure and Properties of Wine Pigments and Tannins. Am. J. Enol. Vitic. 2006, 57, 298-305.

16. Atanasova, V.; Fulcrand, H.; Le Guernevé, C.; Cheynier, V.; Moutounet, M. Structure of a New Dimeric Acetaldehyde Malvidin-3-Glucoside Condensation Product. Tetrahedron Lett. 2002, 43, 6151-6153. [CrossRef]

17. Oliveira, J.; Mateus, N.; de Freitas, V. Previous and recent advances in pyranoanthocyanins equilibria in aqueous solution. Dyes Pigm. 2014, 100, 190-200. [CrossRef]

18. González-Arroyo, E.; Pascual, O.; Kontoudakis, N.; Esteruelas, M.; Esteve-Zarzoso, B.; Mas, A.; Canals, J.M.; Zamora, F. Oenological consequences of sequential inoculation with non-Saccharomyces yeasts (Torulaspora delbrueckii or Metschnikowia pulcherrima) and Saccharomyces cerevisiae in base wine for sparkling wine production. Eur. Food Res. Technol. 2015, 240, 999-1012. [CrossRef]

19. Sun, S.Y.; Gong, H.S.; Jiang, X.M.; Zhao, Y.P. Selected non-Saccharomyces wine yeasts in controlled multistarter fermentations with Saccharomyces cerevisiae on alcoholic fermentation behaviour and wine aroma of cherry wines. Food Microbiol. 2014, 44, 15-23. [CrossRef] [PubMed]

20. Rapp, A.; Mandery, H. Wine aroma. EXperientia 1986, 42, 873-884. [CrossRef]

21. Rapp, A.; Versini, G. Influence of nitrogen compounds in grapes on aroma compounds of wines. In Developments in Food Science; Charalambous, G., Ed.; Elsevier B.V: New York, NY, USA, 1995; Volume 37, pp. 1659-1694, ISBN 978-0-444-82013-6.

22. Peinado, R.; Moreno, J.; Medina, M.; Mauricio, J. Changes in volatile compounds and aromatic series in sherry wine with high gluconic acid levels subjected to aging by submerged flor yeast cultures. Biotechnol. Lett. 2004, 26, 757-762. [CrossRef] [PubMed]

23. Benito, S.; Morata, A.; Palomero, F.; Gonzalez, M.; Suárez-Lepe, J.A. Formation of vinylphenolic pyranoanthocyanins by Saccharomyces cerevisiae and Pichia guillermondii in red wines produced following different fermentation strategies. Food Chem. 2011, 124, 15-23. [CrossRef]

24. Bartowsky, E.J.; Henschke, P.A. The "buttery" attribute of wine-diacetyl-desirability, spoilage and beyond. Int. J. Food Microbiol. 2004, 96, 235-252. [CrossRef] [PubMed]

25. Vilanova, M.; Genisheva, Z.; Masa, A.; Oliveira, J.M. Correlation between volatile composition and sensory properties in Spanish albariño wines. Microchem. J. 2010, 95, 240-246. [CrossRef]

26. Duarte, W.F.; Amorim, J.C.; Schwan, R.F. The effects of co-culturing non-Saccharomyces yeasts with S. cerevisiae on the sugar cane spirit (cachaça) fermentation process. Antonie van Leeuwenhoek 2013, 103, 175-194. [CrossRef] [PubMed]

27. Boss, P.K.; Pearce, A.D.; Zhao, Y.; Nicholson, E.L.; Dennis, E.G.; Jeffery, D.W. Potential grape-derived contributions to volatile ester concentrations in wine. Molecules 2015, 20, 7845-7873. [CrossRef] [PubMed]

28. Ramize, F.; Roustan, J.L.; Sablayrolles, J.M.; Barre, P.; Dequin, S. Glycerol overproduction by engineered Saccharomyces cerevisiae wine yeast strains leads to substantial changes in by-product formation and to a stimulation of fermentation rate in stationary phase. Appl. Environ. Microb. 1999, 65, 143-149.

29. Celińska, E.; Grajek, W. Biotechnological production of 2,3-butanediol-Current state and prospects. Biotechnol. Adv. 2009, 27, 715-725. [CrossRef] [PubMed]

30. Suárez-Lepe, J.A.; Morata, A. New trends in yeast selection for winemaking. Trends Food Sci. Techol. 2012, 23, 39-50. [CrossRef]

31. Morata, A.; Gómez-Cordovés, M.C.; Colomo, B.; Suárez, J.A. Pyruvic acid and acetaldehyde production by different strains of Saccharomyces cerevisiae: Relationship with vitisin A and B formation in red wines. J. Agric. Food Chem. 2003, 51, 6475-6481. [CrossRef] [PubMed] 
32. Dipalmo, T.; Crupi, P.; Pati, S.; Clodoveo, M.L.; Di Lucca, A. Studying the evolution of anthocyanin-derived pigments in a typical red wine of Southern Italy to assess its resistance to aging. LWT-Food Sci. Technol. 2016, 71, 1-9. [CrossRef]

33. Vergara, C.; Mardones, C.; Hermosín-Gutiérrez, I.; von Baer, D. Comparison of high-performance liquid chromatography separation of red wine anthocyanins on a miXed-mode ion-eXchange reversed-phase and on a reversed-phase column. J. Chromatogr. A 2010, 1217, 5710-5717. [CrossRef] [PubMed]

34. He, F.; Liang, N.; Mu, L.; Pan, Q.; Wang, J.; Reeves, M.J.; Duan, C. Anthocyanins and their variation in red wines II. Anthocyanin derived pigments and their color evolution. Molecules 2012, 17, 1483-1519. [CrossRef] [PubMed]

35. Suárez-Lepe, J.A.; Morata, A. Yeasts for Red Winemaking [Levaduras para Vinificación en Tinto], 1st ed.; AMV Ediciones: Madrid, Spain, 2015; pp. 158-166, ISBN 978-84-943451-9-7.

36. Asenstorfer, R.E.; Hayasaka, Y.; Jones, G.P. Isolation and structures of oligomeric wine pigments by bisulfite-mediated ion-eXchange chromatography. J. Agric. Food Chem. 2001, 49, 5957-5963. [CrossRef] [PubMed]

37. Eglinton, J.; Griesser, M.; Henschke, P.; Kwiatkowski, M.; Parker, M.; Herderich, M. Yeast-mediated formation of pigmented polymers in red wine. ACS Symp. Ser. 2004, 886, 7-21.

38. Dallas, C.; Ricardo-da-Silva, J.M.; Laureano, O. Products formed in model wine solutions involving anthocyanins, procyanidin B2, and acetaldehyde. J. Agric. Food Chem. 1996, 44, 2402-2407. [CrossRef]

39. Chen, K.; Escott, C.; Loira, I.; del Fresno, J.M.; Morata, A.; Tesfaye, W.; Calderón, F.; Suárez-Lepe, J.A.; Han, S.; Benito, S. Use of non-Saccharomyces yeasts and oenological tannin in red winemaking: Influence on colour, aroma and sensorial properties of young wines. Food Microbiol. 2018, 69, 51-63. [CrossRef] [PubMed]

40. Abalos, D.; Vejarano, R.; Morata, A.; González, C.; Suárez-Lepe, J.A. The use of furfural as a metabolic inhibitor for reducing the alcohol content of model wines. Eur. Food. Res. Technol. 2011, 232, 663-669. [CrossRef]

41. Morata, A.; Loira, I.; Heras, J.M.; Callejo, M.J.; Tesfaye, W.; González, C.; Suárez-Lepe, J.A. Yeast influence on the formation of stable pigments in red winemaking. Food Chem. 2016, 197, 686-691. [CrossRef] [PubMed]

42. Somers, T.C.; Evans, M.E. Spectral evaluation of young red wines: Anthocyanin equilibria, total phenolics, free and molecular $\mathrm{SO}_{2}$, "chemical age". J. Sci. Food Agric. 1977, 28, 279-287. [CrossRef]

Sample Availability: Samples of the compounds are not available from the authors.

(C) 2018 by the authors. Licensee MDPI, Basel, Switzerland. This article is an open access article distributed under the terms and conditions of the Creative Commons Attribution (CC BY) license (http://creativecommons.org/licenses/by/4.0/). 